\title{
Support Offered at Registration for Open Distance Learning (ODL) Students: A Potential Good or a Mismanaged Evil?
}

\author{
Bobo Segoe \\ University of South Africa \\ College of Education \\ Email: segoeba@unisa.ac.za
}

\section{Doi:10.5901/mjss.2014.v5n4p705}

\begin{abstract}
The aim and purpose of this study is to focus on modal proposition that support given at registration, in the context of distance education (DE), has the potential to enhance learning and retention among students, but has as yet to reach its valid zenith of utility value in didactical practice. A key conventional ODL organisation has been, and still is, quality learner support services that are given at registration and therefore enhancing smooth transition process particularly to new students. Unfortunately, over recent years, because of high increases in the enrolment numbers of ODL students in various educational institutions, it has highly become difficult to implement quality orientation programmes for students. This study seeks to identify the methods that can be more helpful to support ODL students and the praxis concept that is central to them particularly during registration. Empirically, the study explores the perceptions of National Professional Diploma in Education (NPDE) teachers studying at a distance at the University of South Africa (Unisa) regarding the support they receive at registration. Results show that students do not receive adequate support during registration and that they need a well planned registration support so that they can feel a sense of belonging which will prepare them for the new venture.
\end{abstract}

Keywords: Distance Education, Tutors, Students, registration support, conventional system, Open Distance Learning

\section{Introduction}

One of the innovations that has taken place in the field of higher education is the emergence of ODL. According to Ofoha (2012) ODL is one of the most rapidly growing fields of education and its potential impacts on all education delivery systems has been greatly accentuated through the proper management, planning and constant development of quality support services such as those offered to students at registration. Registration support in ODL context refers to the meeting of needs which all students aspire for, because they are central to high quality learning such as guidance about course choice, preparatory diagnosis, study skills, study loans or access to group learning in seminars and tutorials (Thorpe, 2002). These are the elements in systems of the entire support services that many practitioners should see as essential for effective provision of ODL (Keegan, 1996).

In most African countries and South Africa particularly, there is a high demand of alternative mode of delivery as majority of youth that are qualified for admission to conventional system cannot do so because of lack of space and finance. It is also obvious that due to limitations in both human and material resources, conventional institutions can no longer satisfy the snowballing population of a country like South Africa. Consequently, the emergence of ODL has marked a turning point in the provision of educational opportunities for millions of people that have been left out of the conventional system. Against this background, it has become increasingly necessary that services such as registration support, Information Communication Technology (ICT), tutor support or peer support be carefully developed and properly managed and maintained if ODL provision is to be relevant and recognised as complimentary to conventional higher education mode of teaching. The success of any ODL programme, inter alia, depends not only on how well it is designed or offered but also on how students are orientated right from the outset.

Let's face it: In an ODL setting it is not difficult for quality improvement initiatives such as registration support to acquire a bad name. My personal experience, as an ODL lecturer, is littered with stories of poor support initiatives at registration in DE institutions which, in most cases, yield questionable results, and in some cases, the entire student support initiatives have been dismissed as a complete waste of time and money. Whilst research on student support concludes that quality registration support is a powerful tool for motivating students and therefore improves retention rate, particularly in $D E$ institutions, there has been a great deal of passionate dissent about how quality registration support 
should be planned, managed and implemented. The road so far has been described as "tumultuous" and continues to be so. Given this challenge, it certainly means vigilance and effective planning in organisational terms rather than mere continuity and hard structures in activities related to registration support are needed.

Furthermore, it boils down to differentiation rather than uniformity and consistency and in organisational terms it represents moving from product to service and in quality assurance terms it represents the centrality of the customer, who in this case is a student. It means that in a whole range of different settings of support offered at registration, innovative ideas should always be at the forefront which could turn organisational thinking upside down. The organisation and function of registration support services in ODL lie at the nexus of change. Therefore, this study is tempted to embrace a high level of performance-based, efficiency-driven and results-oriented strategies in the entire organisation of services to be offered at registration in an ODL environment. Such strategies, contend Johnson \& Cross (2004), could use explicit goals and measurable targets to deal with problematic issues. I do not suggest performance here in its narrow sense as just setting goals and targets and the necessary performance indicators but performance as entailing putting in place innovative strategies, recruiting suitable staff, continuously training this staff, setting clear procedures, compiling registration guides, establishing and enabling strategies and procedures as well as setting in motion appropriate registration processes.

Against this background, this study argues that support offered at registration which is not properly planned, managed and which is not innovative in any ODL setting is doomed to failure. It may prove disastrous to much-needed institutional rejuvenation. Transforming the ODL sector to meet present and future challenges is not easy. It entails changing public perceptions and attitudes regarding this sector. It requires critical rethinking and reinterpreting the present situation in ODL institutions in aspects such as support offered to students at registration.

This paper presents a critical analysis of registration support as an important support structure for ODL students. It hopes to enlighten the reader on how issues of registration support affect ODL students at higher education institutions. The first section of this article gives a brief description of the background and the context of the study, highlighting the overview and the importance of registration support as an important student support service in the ODL context based on the literature reviewed. This is followed by the research methodology and findings from fieldwork conducted with NPDE students at UNISA (South Africa). The findings are discussed with the focus on distinct areas for improvement on registration support as an important support strategy for teachers studying at a distance. At the end of the article, conclusions are presented and suggestions made on how registration support as a support measure for ODL student teachers may be improved.

\section{Background to the Study}

The NPDE teachers' course is a South African 360 credit qualification, on level 5 of the National Qualification Framework (NQF). It is a three year DE qualification programme that has been designed not only to upgrade the qualifications of teachers, but also to equip them with the professional competencies relating to teaching and learning in schools. UNISA was one of the higher education institutions which were requested to incorporate NPDE course in its curricula since 2002. Much as the university encourages students to register online, there are those that still register in person. This study confines itself to this particular group of students. However, I strongly content that even those that register online, need quality registration support. The nature of the NPDE qualification as a DE programme, the way in which the curriculum has been developed and the requirements for its implementation, have all necessitated that the registration process should be of value to students and equally, it should be done in such a way that at the end, students understand what the intended course entails.

A key conventional DE organisation has been, and still is, proper student support systems that are given during registration with the sole purpose of enhancing a smooth registration process (Kuboni, 2009). For example, as part of the registration process, tutors and programme co-ordinators could conduct workshops or orientation sessions with newly enrolled students, where they could familiarise and motivate them about their intended field of study. That is why Barker \& Crawley (2005) conclude that at registration, there is a clear need for high quality information, advice and guidance from the registration personnel. Barker \& Crawley (2005) further contend that particularly at first registration, ODL students need information on aspects such as their course structure, organisation or planning their work load, thereby gaining an overview of the course.

Research shows that providing intensive and well-organised support for beginning students through friendly atmosphere, mentoring, accurate information, counselling or induction programmes, can lead to high rates of retention (Brewster \& Railsback, 2001). Brewster \& Railsback (2001:27) further emphasise that "series of information and 
counselling sessions could be organised prior to registration in order to give students some background regarding a particular programme so that when they register, they already know what their intended field of study entails".

Kretovics (2003) warns that DE students have to receive adequate support at registration from both academic and administrative staff as this can be of great benefit to them. Registration support could be in the form of giving advice, issuing registration materials brochures and calendars and study materials (tutorial letters, study guides or prescribed books) to registering students. These support services could be used to clarify regulations, help in choosing relevant courses, motivate, build self-esteem, improve campus identity, create opportunities for interpersonal contacts and provide access to other learning support services. Kretovics (2003) further emphasises that students have to get all registration and study materials right at registration, that is, in time so as to embark on their studies as early as possible. Kretovics (2003) concludes by stating that the provision of proper support, particularly at registration, will increase the probability of academic success.

For many students, entering higher education institutions is a major transition and yet they sometimes get little or no registration support as they attempt to deal with this new experience. All DE students therefore must be given proper guidance and accurate information during registration as this will make them feel more comfortable (Qakisa-Makoe, 2005). In addition, students need proper registration support as they go through life, especially when undergoing a major change such as entering into study programmes at university level. It goes without saying that DE institutions such as UNISA should be service-orientated in order to address access needs. In a service-orientated institution, a student or a client would be central to the learning process.

At registration, support may also take place where prospective students are supported by a counsellor dealing with their initial inquiry. They are usually given an overview of the course so that they can carefully decide whether the course is in fact suitable to them or not. The advisor could answer queries students may have, provide accurate and correct information and may also help them with the completion of registration forms. As a result, these advisors have to be trained continuously so that they can display a measure of acceptable ethics to students, friendly atmosphere and be approachable. Mishra (2003) asserts that at this stage, students require encouragement and they also need their confidence boosted.

\section{Theoretical Framework}

The theory of social constructivism as a learning process is used as the guiding framework for understanding the phenomenon under this study better. The lens of socialisation is utilised in order to grasp better the process by which one comes to be accepted as an ODL student. For example, students enrolling for the first time at an ODL institution will interact with registration personnel in the process of socialisation. In this way learning occurs when these students are engaged in social registration activities (McMahon, 1997). Therefore, socialisation can be defined as the process through which individuals learn the values, attitudes, norms, knowledge and behaviours to be accepted into a particular organisational structure (Gardner \& Blackstone: 2013), in this case, ODL student. Tierney \& Rhoads (1994:52) state "it is the socialisation of an individual that makes up the sum total of values and norms that directs a person's daily responses and behaviour patterns".

Socialisation is often seen as a two phase process, initial entry and role continuance (Tierney \& Bensimon, 1996). Initial entry occurs when the individual enters the organisation or, in the context of this study, the newly enrolled student who enters the ODL institution and begins to "learn the ropes" of the department, discipline and the institution through the support the student receives at registration. Anticipatory socialisation occurs after the registration process, which allows a student to begin acquiring values, norms, attitudes and beliefs of the discipline and the desired profession, the transmission of the particular attitudes, actions and values of the ODL institution, that is, anticipatory socialisation will occur in the early months and years of the student's enrolment. Much as these two phases of socialisation cannot necessarily be easily separated, this study confines itself to initial entry phase, as it encompasses activities dealing with support received at registration.

The process of registration support services need to receive quality planning and be managed meticulously. In most ODL institutions, orientation timetables are rarely spelled out, resulting in a variable process; and while increasing emphasis is being placed in high students enrolment, support received at registration has traditionally been a disjunctive process which often results into student's drop-out and poor performance (Tierney \& Rhoads, 1994). Therefore, when registration support services are viewed through the lens of socialisation in ODL institutions, it is apparent that these services may be imbued with haphazard individual approaches that are informal and random. As Fraser \& Killen (2005) argue, this may adversely affect the processes of students' progression and persistence in, and also increase attrition 
and drop-out rates in such institutions. Zulu (2008) attests that attrition and drop-out factors have been of serious concern for several decades, and have influenced studies on post-enrolment criteria affecting students' academic success or failure.

The theoretical framework of socialisation allows for deeper understanding of the process of quality registration support and factors that may influence successful and an unsuccessful attempt to implement it. Indeed, this perspective is missing in literature about how to design and implement quality and well-organised registration support process particularly in ODL institutions. Importantly, the voices of those who have experienced the process, like students, are missing from the literature.

\section{Research Method}

\subsection{Research questions}

The research questions for this study were as follows:

- What were the experiences of NPDE students about support they received at registration?

- What is the role or the importance of registration support for ODL students? order to:

Following Maxwell's (1996:17) understanding of qualitative research and its purposes, I utilised this approach in

- Understand the meaning, for participants in the study, of events, situations and actions they are involved with and of the accounts that they give of their lives and experiences

- Understand the particular context within which the participants act, and influence that this context has on their actions

- Understand the process by which events and actions take place

- Identify the importance of the phenomenon and its influences

As such, I focussed my research examination in one institutional setting, referred to as UNISA, which is the biggest ODL higher education institution in South Africa. UNISA is one of the universities which were requested by the South African Department of Education to incorporate NPDE course in its curriculum since 2002. The NPDE programme is a 360 credit South African qualification on level 5 of the National Qualification Framework (NQF). Its curriculum is structured in such a way that it focuses on classroom activities and also equips upgrading teachers with the foundational, practical and reflective competencies required for study at NQF level 6 . Right from the outset, it was agreed that the mode of delivery for this intervention or upgrading qualification had to be DE. NPDE programme is accredited by the Department of Education. The researcher had been an NPDE lecturer for seven years and therefore had complete access to all centres.

\subsection{Participants}

The participants were 30 NPDE final year students at UNISA. The researcher was purposeful in his selection as he wanted to understand the experiences of final year students who had been exposed to as many registration processes as possible in their different levels of study. As represented in the following table, the participants were selected from the four registration centres of NPDE in South Africa, namely Durban, Pretoria, Polokwane and Nelspruit and participated in a focus group interview. Pretoria is the biggest registration centre, followed by Durban.

Table 1: Sampling profile for the focus group interview at each centre

\begin{tabular}{|c|c|c|c|}
\hline NAME OF THE REGISTRATION CENTRE & NUMBER OF PARTICIPANTS & YEAR OF STUDY & LEVEL OF STUDY \\
\hline Pretoria & 10 & 2011 & Final year students \\
\hline Durban & 8 & 2011 & Final year students \\
\hline Polokwane & 6 & 2011 & Final year students \\
\hline Nelspruit & 6 & 2011 & Final year students \\
\hline TOTAL & 30 & & \\
\hline
\end{tabular}




\subsection{Data Collection}

Focus groups were chosen because compared to other forms of qualitative methods such as single interviews, they permit analysis not only of statements and reports of experiences and events, but also of the interactional context in which these statements and reports are produced (Flick: 2007). Additionally, it has been argued that "focus groups may provide quality controls because participants tend to provide checks and balances on one another that serve to curb false or extreme views" (Patton, 2002:67). The sample represented natural diversities as it included male and female students with different experiences and age groups and participants came from different geographic places of South Africa. After obtaining informed consent, the researcher conducted face-to-face interviews with the four focus groups. Guided by a semi-structured protocol that asked the participants to provide details of their experiences about the registration process at UNISA, each group interview session lasted for 60 minutes.

\subsection{Data analysis}

Interview session discussions were audio-taped and then transcribed verbatim. Thereafter, the constant comparative method (Merriam, 1998) was used to analyse the focus group data. The constant comparative analysis allows a researcher to format and transcribe the data into a readily identifiable, readable and structured format. This analysis uses systematic steps of identifying key points, followed by comparing these points with those of other focus group members in order to identify patterns (Meegan et al, 2013). This structure ensured that what was presented was an accurate reflection of the focus group participants' interviews.

Data was reduced in order to determine themes so as to understand the larger dynamics about services given during registration periods at UNISA. Using the constant comparative method, similar themes from the four contact lesson centres were grouped together under headings. In this way, areas of importance and significance in relation to the support given at registration were identified.

Merriam (1998) asserts that providing readers with a rich, thick description permits them to determine how closely their situations match the research situation, and hence, whether findings can be transferred. The use of in-depth description in portraying a particular phenomenon allows for transferability by the reader, thus enhancing external validity. External validity was achieved in the present study by providing rich, thick descriptions through direct quotes from NPDE students regarding their experiences and perceptions of the registration support they received during different levels of their study at UNISA.

\section{Results and Discussion}

Results are presented under four themes that emerged from the data: (a) Orientation and counselling; (b) Information provided to students at registration; (c) Staff attitude during registration and (d) Registration materials.

\subsection{Orientation and Counselling}

Few participants, particularly those from Durban, indicated that they received minimal orientation and counselling at registration. By way of probing, all focus groups were asked the following question at the beginning of each focus group interview session: "What is your experience about orientation and counselling during registration process at UNISA?" Participants in all centres, except for those from Pretoria Centre, were unanimous that there was no orientation session as part of the registration process. In the participants own words:

...we were not guided in how to study our new courses and how to write assignments... we were not even given the opportunities to ask questions and to connect with hundreds of new classmates.

Participants said that during registration, there were administrators who attempted to explain choice of courses of the NPDE programme. From their observation, some of the registration personnel "look like students and know nothing about NPDE". Based on this response, it was clear that NPDE students needed full information from well-trained personnel through well-organised orientation sessions.

Participants felt that they needed proper advice particularly during first year registration so that these advisers or counsellors could coach and orientate them as to the "university life" such as new study methods or writing of assignments. The above sentiment, agrees with Phillips's (2003:46) view that "learners in DE education seriously need 
quality information and admission guidance prior to enrolment as well as the support about their course choices and qualification planning". Emphasising the needs for first year ODL students, Phillips (2003) further states that course induction is vital as some of the learners could be experiencing their first exposure to study at a distance. Qakisa-Makoe (2005) supports the above sentiment when she contends that, during registration in ODL courses, tutors or programme co-ordinators could conduct informative orientation sessions with prospective students, where they induct and motivate them about their intended field of study. For many students, entering higher education institutions is a major transition and therefore effective registration support such as counselling is needed in order to reduce attrition and enhance retention.

The majority of the participants indicated that they did not receive counselling at registration and that discouraged them. In the participants' own words:

We need to be advised by well-trained counsellors concerning our studies and how to approach our work...this will help us to be successful.

ODL programmes have been one of many educational innovations related to teacher development processes in higher education institutions such as UNISA. The provision of sound orientation and counselling support at the very beginning, that is, at registration, will go a long way to motivate the students to persist with their studies in later years. Students need to be guided and orientated properly, particularly at first registration of their programme, so as to understand and be familiarised with what they are just about to be involved in. Support may be given by trained counsellors who may deal with the students' initial inquiries and who can also give them an overview of the course.

\subsection{Information provided to students at registration}

NPDE students' responses (from all centres) with regard to information they got at registration showed much dissatisfaction. The majority of the participants indicated that they did not receive satisfactory information during registration. They reported that most of the personnel at registration venues were confused and did not understand the rules and regulations governing NPDE as a programme. As a result, wrong information was disseminated, to the extent that some of them were registered either in a wrong academic level, for wrong modules or for an incomplete number of modules. This they mainly attributed to the incorrect information they received at registration. One of the participants from Durban described it this way:

... Not enough information when you come to register. Assistants do not know anything about NPDE. Please train them. For example, when I came to register for the first time in 2007, they put me in level 2. After I had finished level 2 and 3, I received a letter from UNISA which stated that I had to do level 1modules. I had to do them to complete my diploma. This is really frustrating.

One participant, from Polokwane, echoed the above by remarking as follows:

For registration, I found difficulties. When I went for my first time of registration, I told the lady who was there in the computer room that I wanted to register for Foundation Phase, but she registered me in Senior Phase. Now I have got a life problem. In my school, I am in the Foundation Phase but I am completing my Senior Phase programme this year.

Another participant from Nelspruit stated that:

... administration support was a nightmare, because I was always wrongly registered or registered in the wrong language. When I tried to fix it at Nelspruit, I was always referred to Pretoria. They said I must go to the main campus to fix it there. In most cases, I did not have the time and money in my hands to go to Pretoria. At the end, I ended up leaving it.

The above findings show that what is advocated by Brewster \& Railsback, 2001) and Barker \& Crawley (2005) when they state that students at registration need to be given quality and correct information has not been put into practice. Qakisa-Makoe (2005) argues that first year DE students in particular, are in a transitional phase as they attempt to deal with new experiences. As a result, information supplied by administrators at registration has to be accurate and beneficial to them. Failure to supply this may result in students registering for wrong modules or for wrong levels of study. The underlying principle is that the administrative personnel dealing with registration matters need to be properly trained and well informed about the rules and regulations of any DE programme so that they can discharge quality information to 
the students during registration.

On the other hand, a number of participants indicated that they were fairly satisfied with the information they received from administrators during the registration process. Interestingly, most of those students are the ones who normally registered at the main campus in Pretoria. One of the participants from Pretoria described the information process as follows:

People at administration are doing very well. The support from these people is very good. They will welcome you, give you proper information and show you the queue so nicely and with due respect.

Pretoria participants stated that personnel at registration points helped them with things such as completion of registration forms, choice of courses and gave them the necessary registration materials such as calendars and registration brochures.

\subsection{Staff attitude during registration}

Most participants complained that the administrators at registration centres were not approachable and could not answer most of their questions. Students alluded to the fact that some administrators, particularly in Durban and Nelspruit, were short-tempered and unfriendly and as a result could not give them enough information and guidance they needed. This was evidenced by the following comment from one of the participants from Durban:

\section{People at registration do not speak to us nicely. Their attitude is not good. They give us insufficient information and they are not friendly to us.}

The comment above shows dissatisfaction of NPDE students concerning staff attitude which emerged as a dominant feature amongst Nelspruit, Durban and Polokwane participants. Most participants said that the staff working at registration counters is either not properly trained or not motivated as some of them seemed to be rude and shorttempered.

When probed further, participants stated that some of the registration personnel were not familiar with the contents of NPDE registration brochures which made them to be agitated when asked for clarifications. The above sentiment was shared by participants from Durban when they commented:

\section{... during registration rules and regulations are not properly communicated to us and this is frustrating. When asked a question, the staff became angry.}

To confirm this, the focus group from Polokwane stated as a problem:

Incorrect registration and the negative attitude we receive during registration. In most cases, we are ill-advised during registration. No friendly approach is received at registration.

Registration personnel need to be friendly and show positive support and respect to the learners at all times. This will help the learners to feel accepted and in this way, their confidence will be boosted. The communication must be cordial and effective and a positive relationship between administrators and registering students is of utmost importance during registration. This kind of cordial relationship will increase the probability of academic success and build positive self-esteem.

However, participants from the Pretoria centre indicated that they were satisfied with the attitude of administrators conducting registration duties. The majority of NPDE students from Pretoria felt that the process of registration was wellorganised. These participants said that the process of walk-in registration was fairly quick and the administrators were ready to help them, for example by showing them the correct queues to stand in. This, they echoed, was done in a friendly and courteous manner.

\subsection{Registration Materials}

From what was gathered from the data on registration materials, most participants agreed that information in the printed calendar was mostly incorrect, outdated and confusing. Unisa supplies students with envelopes and writing pads to use for their assignments. In most cases, envelopes and assignments pads were not available at registration. Envelopes and 
assignments pads were sent very late or were not sent at all. As a result, students had to purchase them and that brought a lot of dissatisfaction. This was confirmed by the following comment from one of the participants in Durban:

Most of the time I registered at the beginning of the year but I always received my study material in May with no writing pads and envelopes. I had to buy for myself. This is not fair.

The above sentiment is supported by participants from Pretoria when they indicated that:

......insufficient or no supply of study materials e.g. envelopes and assignment pads... this affected us badly.

From the above remarks it is evident that some NPDE students did not receive enough envelopes and assignment pads or did not receive them at all. This was unacceptable to them. Some of the students indicated that at times they waited for envelopes and assignment pads for a long time and that delayed their assignment submission. As a result they ended up submitting late. The majority of the participants complained that the costs of all assignment pads and envelopes were included in their fees and it was totally unfair to be required to buy them from suppliers while they had already paid for them.

It would appear that UNISA regarded assignment pads and envelopes as insignificant or as just another "add on materials" needed to support meaningful learning in ODL. This negated the principle of proper planning of effective learner support structures as advocated by Kelly \& Fage (2002:27) when they emphasise that "any learner support material should be perceived as an integral part of the planning and delivery of quality ODL courses and should never be regarded as an added-on aspect". Kelly \& Fage (2002) further contend that learner support material must be available at every stage of a learner's career and that all support possibilities need to be timely and be tailored so as to be most appropriate to meet students' needs.

Study materials such as tutorial letters, which normally contain assignments and study hints, as well as study guides and prescribed books, are supposed to be given to students during registration. Most participants felt that they did not get all study materials at registration. Some tutorial letters and study guides arrived late, which impacted negatively on their submission dates, to an extent that they handed in their assignments late. Ultimately, their marked assignments were sent to them late, sometimes even after they had written the examinations. Participants were not happy as one of them from Polokwane concurred:

My assignments were always late because of tutorial letters and study guides that came late.....this affected my studies and I failed.

The late receipt of study materials affected the studies of students negatively. In some cases, NPDE students had to write their examinations without the necessary feedback and guidance from their marked assignments. Some handed in their last assignments late and their marks were not captured as the computer system was already closed for data capturing for that academic year. In this case, learners had to battle for such marks to be captured, even if it was not their fault.

From the above analysis, it can be concluded that the support received at walk-in registrations, particularly at registration centres such as Durban, Nelspruit or Polokwane, was not satisfactory. While acknowledging the favourable comments by few NPDE students, the areas of dissatisfaction are to be considered as a cause for concern. Based on some of the comments from the participants, it is a grave concern to realise that some NPDE students ended up dropping out.

All participants from the Pretoria centre were unanimous that, generally, the support they received at registration was satisfactory, whereas the majority of their counterparts from other centres (Durban, Nelspruit and Polokwane) complained bitterly about the assistance they received at registration. It can be assumed that the personnel dealing with registration matters in Pretoria seemed to be well conversant with the rules and regulations governing NPDE programmes. Apparently, and as head office staff, they received regular training and support pertaining to ever-changing registration procedures, unlike their colleagues at regional centres, who seemingly got minimal or no support at all.

In some cases, at regional centres like Durban, students were registered for wrong modules or wrong levels and this adversely affected their teaching performance at their prospective schools. For example, an NPDE student who was wrongly registered for an intermediate phase, but taught a foundation phase class at her school, would be negatively affected in her daily teaching work. Obviously, some of the teaching techniques or strategies were not applicable to her real practical situation. 
Given the general dissatisfaction of NPDE students pertaining to the support they got at registration, it follows that these students had serious difficulties in proceeding with their studies. If any student was wrongly registered, particularly at first registration, he or she was likely to fail or drop out. For example, some of the NPDE students indicated that during their first year registration, they were wrongly allocated second year modules. After passing the second year modules, they were requested to revert back to first year modules. Obviously, this was not only frustrating; but adversely affected their performance.

\section{Recommendations}

If registration support programmes have to be cleansed of the stigma of "mere lip service", in ODL then education departments, in different countries, should engage ODL institutions in order to ensure that registration support initiatives, serve its students. On-going planning, monitoring and evaluation mechanisms in identifying strengths, weaknesses and problems of registration support services should be put in place early enough. These programmes should seek ways of addressing anything that might affect the implementation thereof in an adverse way.

The literature study emphasised that students in ODL institutions, and particularly new students, need maximum support at registration. With increased demand for access to $D E$, institutions of higher learning are now increasingly challenged to improve support at registration if they are to develop quality learning services or programmes of high standards that are responsive to students' needs. At registration, it is important that DE students get an opportunity to receive support for any matter that is of concern to them and discuss problems in a supportive and cordial atmosphere. Furthermore, DE students should receive well-resourced guidance and counselling support as well as accurate information concerning their intended programme of study at the time of registration. Staff members that deal with registration issues should show positive support and all study materials should be made available to the students at the very beginning of their study programme.

It is further recommended that each ODL institution should establish or strengthen competent Departments of Guidance and Counselling to take responsibility of guiding and counselling students with life and study matters. Each department should clearly formulate its objectives and orientation programmes that deal with guidance and counselling for students. For example, personnel responsible for this task should clearly indicate how they will implement guidance and counselling activities during an orientation period which is part and parcel of registration. These programmes should be rigorous and be prepared long in advance. These departments should be allocated sufficient resources and time to execute their mandate.

\section{Conclusion}

This study argued that support offered to DE students at registration is very important and that this support should be regarded as crucial. Therefore, the challenge for those involved in DE programmes is to recognise, first of all, the critical value of this support service right from the planning stages of each course, and then to determine how it can best be implemented and managed in order to enhance retention of students and successful learning. The core of the argument here is that by planning registration support service as an integral part of a teaching and learning programme, rather than as an afterthought which can be implemented when times get difficult, DE institutions can demonstrate a clear recognition of the link between income generation and registration support.

While this study added to the sparse literature about the process of support offered at registration in an ODL setting, it was nevertheless not without limitations. The unique context of one institution and the sample which is limited to only one programme of study (NPDE) reduce the generalizability of the findings. Moreover, because of the selfselected sample, the findings could have largely represented the perspectives of individuals who may have had overly negative experiences. Inferences drawn from the self-selected sample, based on one study programme, from the perspectives of students only, are, by their nature, limited in scope. Therefore, future studies could continue to explore the process of registration support and the experiences of all those who engage in it in different contexts and with different constituents.

\section{References}

Barker, P. and Crawley, J. (2005). Providing effective learner support for part-time learners, Research Report: Learning and Skills Development Agency. London: Information and Customer Centre.

Brewster, C. and Railsback, J. (2001). Supporting Beginning Teachers: How administrators, teachers and policymakers can help new 
teachers succeed. Oregon: University College of Oregon.

Flick, U. (2007). Doing Focus groups: The Sage qualitative research kit. London: Sage.

Fraser, W. and Killen, R. (2005). The perceptions of students and lecturers of some factors influencing academic performance at two South African universities, Perspectives in Education Vol. 23, No. 1, 25-40.

Gardner, S. K. and Blackstone, A. (2013). Putting in your time: Faculty Experiences in the Process of Promotion to Professor, Innovations in Higher Education Vol 38, 411-425.

Johnson, B. and Cross M. (2004). Academic leadership under siege: possibilities and limits of executive deanship, South African Journal of Higher Education Vol. 18, No. 2, 34-58.

Keegan, D. (1996). Foundations of Distance Education. London: Routledge.

Kelly, P. and Fage, J. (2002). A framework for student support and Guidance, internal publication: Student Sevices Planning Office, Milton Keynes: Open University Press.

Kretovics, M. (2003). The role of student affairs in Distance Education: Cyber-Services or Virtual Communities, Online Journal of Distance Learning Administration Vol. 4, No. 3, 1-16.

Kuboni, O. (2009). Role of the local centre in strengthening student support in UWI'S distributed learning programmes, Distance Education Vol. 17, No. 2, 119-128.

Maxwell, J.A. (1996). Qualitative Research Design: An interpretive approach. Thousand Oaks, CA: Sage.

McMahon, M. (1997). Social Constructivism and the World Wide Web - A Paradigm for Learning, Paper presented at the ASCILITE Conference. Perth: Australia.

Meegan, S., Dunning, C., Belton, S. and Woods, C. (2013). Teaching Practice: University supervisors' experience and perceptions of a cooperating physical education teacher education programme, European Physical Education Review Vol. 19 No. 2, 199-214.

Merriam, S.B. (1998). Qualitative Research and Case Study Applications in Education. San Franscisco: Jossey-Bass

Mishra, S. (2003). Supporting the student in new teaching and learning environments', British Journal of Technology Vol. 35, No. 2, 241253.

Ofoha, D. (2012). Assuring quality evaluation practices in open and distance learning system: The case of National Open University of Nigeria, Africa Education Review Vol. 9, No.2, 230-248.

Patton, M.Q. (2002). Qualitative Research and Evaluation Methods (3rd ed.). Thousand Oaks, CA: Sage.

Phillips, M. (2003). Delivering learner support on-line: Does the medium affect the message? London: Routledge Falmer.

Qakisa-Makoe, M. (2005). Reaching out: Supporting Black Learners in Distance Education, Progressio Vol. 27, No. 2, 44-61.

Tierney, W.G. and Bensimon, E.M. (1996). Promotion and tenure: Community and socialisation in academe. Albany NY: State University of New York Press

Tierney, W.G. and Rhoads, R.A. (1994). Enhancing promotion, tenure and beyond: Faculty socialisation as a cultural process. Washington DC: George Washington University.

Thorpe, M. (2002). Rethinking Learner Support: the challenge of collaborative online learning, Open Learning Vol. 17, No. 2, 105-119.

Zulu, C. (2008). An exploratory study of first-year students at a historically black university: their academic experiences, success and failure, Africa Education Review Vol. 5 No. 1, 30-46. 